\title{
Variação lexical para os itens calcinha e rouge: um estudo sobre o léxico do português falado pelos Karipuna do Amapá ${ }^{1}$
}

\author{
Lexical variation for calcinha and rouge items: a study on the lexicon of Portuguese \\ spoken by the Karipuna do Amapá \\ Romário Duarte SANCHES* \\ Universidade do Estado do Amapá (UEAP)
}

RESUMO: A região do Oiapoque, localizada no extremo norte do estado do Amapá, é conhecida historicamente por agregar diferentes povos indígenas, caracterizando-se como uma área plurilíngue e pluriétnica. Assim, este estudo tem o objetivo de descrever o português falado por indígenas da etnia Karipuna do Amapá, com foco para variação lexical dos itens calcinha e rouge. O referencial teórico inclui estudos sobre dialetologia, geolinguística e variação lexical (CARDOSO, 2010; COMPOY, 1999; CHAMBERS, TRUDGILL, 1984). No que se refere à metodologia adotada, emprega-se o modelo de Dialetologia Pluridimensional e Contatual (ALTENHOFEN; THUN, 2016), que busca controlar variáveis linguísticas e extralinguísticas. Para coleta dos dados, foram aplicados questionários a 36 colaboradores indígenas distribuídos em nove aldeias da etnia Karipuna do Amapá. Os resultados apontaram que para o item calcinha os entrevistados responderam calcinha, biquíni(biquinho) e anágua, já para o item rouge foram registradas as variantes pó compacto, maquiagem, blush e talco.

PALAVRAS-CHAVE: Dialetologia. Geolinguística. Léxico. Variação linguística.

\begin{abstract}
The Oiapoque region, located in the extreme north of the state of Amapá, has historically been known for bringing together different indigenous peoples, being characterized as a multilingual and multiethnic area. Thus, this study aims to describe the Portuguese spoken by indigenous people of the Karipuna do Amapá, focusing on the lexical variation of the items calcinha and rouge. The theoretical framework includes studies on dialectology, geolinguistics and lexical variation (CARDOSO, 2010; COMPOY, 1999; CHAMBERS, TRUDGILL, 1984). With regard to the methodology adopted, the model of Pluridimensional and Contactual Dialectology is used (ALTENHOFEN; THUN, 2016), which seeks to control linguistic and
\end{abstract}

\footnotetext{
${ }^{1}$ Este estudo traz uma amostra dos resultados encontrados na Tese de Sanches (2020).

* Professor de Linguística na Universidade do Estado do Amapá (UEAP). Doutor e mestre em Letras (Linguística) pela Universidade Federal do Pará (UFPA). E-mail: romario.sanches @ueap.edu.br
}

Revista Moara, n. 55, jan-jul 2020 ISSN: 0104-0944

Recebido em 16/03/2020

Avaliado em 10/07/2020 
extralinguistic variables. For data collection, questionnaires were applied to 36 indigenous collaborators distributed in nine villages of the Karipuna do Amapá. The results showed that for the item calcinha, the respondents answered calcinha, biquíni(biquinho) and anágua, while for the item rouge, the pó compacto, maquiagem, blush and talco variants were registered.

KEYWORDS: Dialectology. Geolinguistics. Lexicon. Linguistic variation.

\section{Introdução}

O estado do Amapá possui um território de 142.828,521 km², com vasta riqueza florestal, hidrográfica e mineral. Sua história está entrelaçada com a história da Amazônia brasileira, região marcada por disputas territoriais, pelo processo de extração e comercialização de especiarias, seguido, pela exploração de minérios.

As fontes históricas do século XVIII e XIX, sobre a formação étnico-cultural do Amapá, registram a presença de descendentes europeus, indígenas e negros. Já no século XX, o Amapá ganha novos habitantes, atraídos pela oferta de empregos. Nesse período, evidencia-se o grande fluxo migratório de pessoas oriundas principalmente dos estados do Pará e do Maranhão.

Em consonância com as características socioculturais dos demais estados da Região Norte, no Amapá são perceptíveis hábitos e costumes, cujos elementos são de origem africana, indígena e europeia (francesa e, em especial, portuguesa). Essa complexidade étnica, retratada de forma geral na história do Brasil, constitui um misto identitário do povo amapaense que, por sua vez, expressa traços linguísticos peculiares, deixados por outros povos, em decorrência do contato cultural inerente ao processo de formação histórica do Estado.

No que diz respeito ao aspecto linguístico, a língua oficial falada no Amapá (além da Língua Brasileira de Sinais - LIBRAS) é o português. No entanto, vale frisar que além desta há outras variedades linguísticas faladas por indígenas na região como é o caso do kheuól, falado por indígenas Galibi-Marworno e Karipuna; o kalinã, por indígenas da etnia Galibi Kalinã; o parikwaki, pelos Parlikur; o wajãpi, por indígenas 
do povo Wajãpi; o apalaí, por indígenas do grupo Apalaí; o tiriyó, por indígenas Tyrió; e o wayana, falado pela etnia Wayana ${ }^{2}$.

Tendo em vista essa situação linguística no Amapá, o objetivo desse artigo é apresentar uma amostra do léxico do português falado por indígenas da etnia Karipuna do Amapá, com foco para variação lexical dos itens calcinha e rouge. O trabalho está dividido em quatro partes, a primeira versa questões teóricas da área da dialetologia, a segunda discorre sobre o povo indígena estudado, a terceira mostra os aspectos metodológicos aplicados na pesquisa e a última parte apresenta os resultados obtidos.

\section{Dialetologia pluridimensional e contatual}

Sobre a definição do campo de estudo, no qual este trabalho se insere, isto é a dialetologia, vale mencionar a distinção estabelecida por Chambers e Trudgill (1984) em relação à dialetologia tradicional, à sociolinguística laboviana e à geolinguística. Para eles, a dialetologia tradicional é eminentemente rural e a sociolinguística laboviana é eminentemente urbana, já a geolinguística é uma linha de investigação interdisciplinar com foco nas características espaciais de uma determinada variedade linguística. Os autores ainda acrescentam afirmando que essa linha inclui três áreas: a geografia linguística (dialetologia tradicional), a dialetologia urbana (sociolinguística laboviana) e a geografia humana (geografia).

Com base nisso, Campoy (1999) considera a geolinguística como uma área de estudo multidisciplinar que se ocupa das relações existentes entre a língua e a geografia, buscando estudar a língua no contexto geográfico, social e cultural. Diante das mudanças sociais e geográficas ocorridas nos últimos séculos, além das novas perspectivas científicas, a dialetologia começou a explorar novas abordagens (teóricas e metodológicas) na intenção de suprir as necessidades do campo de pesquisa.

Altenhofen e Thun (2016) mencionam uma Dialetologia Pluridimensional e Contatual, baseada no modelo de Dialetologia Pluridimensional e Relacional (doravante DPR) (THUN, 1998). Para compreender o que seria essa "nova dialetologia", é

\footnotetext{
${ }^{2}$ As três últimas línguas citadas são faladas pelos povos que habitam o Parque do Tumucumaque, localizado no Amapá e no norte do Pará.
}

Revista Moara, n. 55, jan-jul 2020 ISSN: 0104-0944

Recebido em 16/03/2020

Avaliado em 10/07/2020 
necessário retomar o modelo postulado no final do século XX pelo dialetólogo alemão Harald Thun.

A DPR configura-se como um modelo de pesquisa geolinguística passível de adaptações e que busca relacionar o espaço monodimensional da variação (variação diatópica) com o espaço pluridimensional (mais de uma dimensão variacional). Thun (1998) buscou unir o eixo vertical da variação (sociolinguística) com o eixo horizontal (dialetologia tradicional), sistematizando essa confluência por meio de dimensões e parâmetros linguísticos e não linguísticos, conforme o Quadro 01 . O objetivo central da DPR é atingir o princípio da pluridimensionalidade intrínseco à variação linguística.

Quadro 01 - Dimensões e parâmetros da Dialetologia Pluridimensional e Relacional

\begin{tabular}{|l|l|}
\hline \multicolumn{1}{|c|}{ DIMENSÃO } & \multicolumn{1}{c|}{ PARÂMETRO } \\
\hline Diatópica & Topostático \\
\hline Diatópica-cinética & Contraste entre colaboradores topostáticos e topodinâmicos \\
\hline Diastrática & Classe sociocultural \\
\hline Diageracional & Faixa etária \\
\hline Diassexual & Homem ou mulher \\
\hline Dialingual & Duas ou mais línguas faladas por grupos étnicos diferentes \\
\hline Diafásica & Estilo (resposta espontânea, leitura e conversa livre) \\
\hline Diarreferencial & Diferenças entre a fala objetiva, a forma e a metalinguagem. \\
\hline Diarreligiosa & Prática religiosa \\
\hline Diamésica & Contraste entre a língua escrita e a língua falada \\
\hline
\end{tabular}

Fonte: Thun (2010, p. 514), adaptado pelo autor.

Thun (2005) considera a DPR como uma ciência geral da variação linguística, pois, parte do pressuposto de que o estudo variacionista monodimensional ou bidimensional deve ser estendido ao espaço tridimensional, combinando o eixo horizontal da dialetologia com o eixo vertical da sociolinguística.

Com isso, o autor defende que o termo dialetologia é o mais adequado a se utilizar quando se trata de pesquisa geolinguística pluridimensional, isto é, que busca combinar espacialidade, socialidade e temporalidade das variedades linguísticas. 


\section{O povo indígena Karipuna do Amapá e sua situação sociolinguística}

Nesta seção apresentam-se os dados populacionais e sociolinguísticos da etnia indígena Karipuna do Amapá, na intenção de compreender a situação de bilinguismo/bilingualidade entre os falantes de português e de kheuól.

O povo indígena Karipuna do Amapá reside no extremo norte do estado do Amapá e possui um total de 2.991 indígenas. De modo recente, tem-se o registro de 22 aldeias da etnia Karipuna, localizadas na Terra Indígena Uaçá (ao longo rio Curipi e da BR-156, que liga a capital Macapá ao município de Oiapoque), na Terra Indígena Galibi (ao longo do Rio Oiapoque) e na Terra Indígena Juminã (no Igarapé Juminã ${ }^{3}$ ).

As aldeias Karipuna atualmente registradas ${ }^{4}$ são: Manga, Espírito Santo, Santa Isabel, Açaizal, Kunanã, Ariramba, Taminã, Estrela, Ahumã, Cutiti/Jõdef, Curipi, Japiim, Piquiá, Kariá, Txibidon, Paxiubal, Benoá, Zacarias, Bastion, Encruzo, Pakapuá e Igarapé da Onça. As aldeias Manga, Espírito Santo e Santa Isabel concentram o maior número de famílias, com destaque para a primeira que registra mais de 1.000 indígenas com residência fixa. Abaixo o Quadro 02, sintetizando as informações supracitadas.

Quadro 02 - População indígena Karipuna do Amapá

\begin{tabular}{|c|c|c|c|}
\hline ALDEIA & LOCALIZAÇÃO & TERRA INDÍGENA & POPULAÇÃO \\
\hline 1. Manga & Rio Curipi & Uaçá & 1014 \\
\hline 2. Espírito Santo & Rio Curipi & Uaçá & 602 \\
\hline 3. Santa Isabel & Rio Curipi & Uaçá & 371 \\
\hline 4. Açaizal & Rio Curipi & Uaçá & 118 \\
\hline 5. Kunanã & Igarapé Juminã & Juminã & 96 \\
\hline 6. Ariramba & Rio Oiapoque & Galibi & 88 \\
\hline 7. Taminã & Rio Curipi & Uaçá & 87 \\
\hline 8. Estrela & BR 156 & Uaçá & 80 \\
\hline 9. Ahumã & BR 156 & Uaçá & 78 \\
\hline 10. Cutiti/Jõdef & Rio Curipi & Uaçá & 65 \\
\hline 11. Curipi & BR 156 & Uaçá & 64 \\
\hline 12. Japiim & Rio Curipi & Uaçá & 60 \\
\hline 13. Piquiá & BR 156 & Uaçá & 48 \\
\hline
\end{tabular}

\footnotetext{
${ }^{3}$ Afluente do rio Oiapoque.

${ }^{4}$ Dados cedidos pela Coordenação Regional Amapá e Norte do Pará (CRANP) da Fundação Nacional do Índio (FUNAI).
}

Revista Moara, n. 55, jan-jul 2020 ISSN: 0104-0944

Recebido em 16/03/2020

Avaliado em 10/07/2020 


\begin{tabular}{|l|l|l|l|}
\hline 14. Kariá & BR 156 & Uaçá & 47 \\
\hline 15. Txibidon & Rio Curipi & Uaçá & 43 \\
\hline 16. Paxiubal & Rio Curipi & Uaçá & 39 \\
\hline 17. Benoá & Rio Curipi & Uaçá & 30 \\
\hline 18. Zacarias & Rio Curipi & Uaçá & 21 \\
\hline 19. Bastion & Rio Curipi & Uaçá & 12 \\
\hline 20. Encruzo & Rio Curipi & Uaçá & 12 \\
\hline 21. Pakapuá & Rio Curipi & Uaçá & 10 \\
\hline 22. Igarapé da Onça & Rio Curipi & Uaçá & 6 \\
\hline \multicolumn{2}{|l|}{ TOTAL } & 2.991 \\
\hline
\end{tabular}

Fonte: Sanches (2020).

Para ilustrar a localização das aldeias Karipuna, tem-se a Figura 01, apresentando quatro áreas de concentração das famílias desta etnia. A primeira (1) está localizada na TI Uaçá, no curso do Rio Curipi, somando 15 aldeias. A segunda (2), também na TI Uaçá, mas percorrendo a BR-156, com cinco aldeias. A terceira (3), diz respeito à TI Galibi, no Rio Oiapoque, com uma aldeia. E a última área (4), localizada na TI Juminã, no Igarapé Juminã, com uma aldeia.

Figura 01 - Aldeias Karipuna

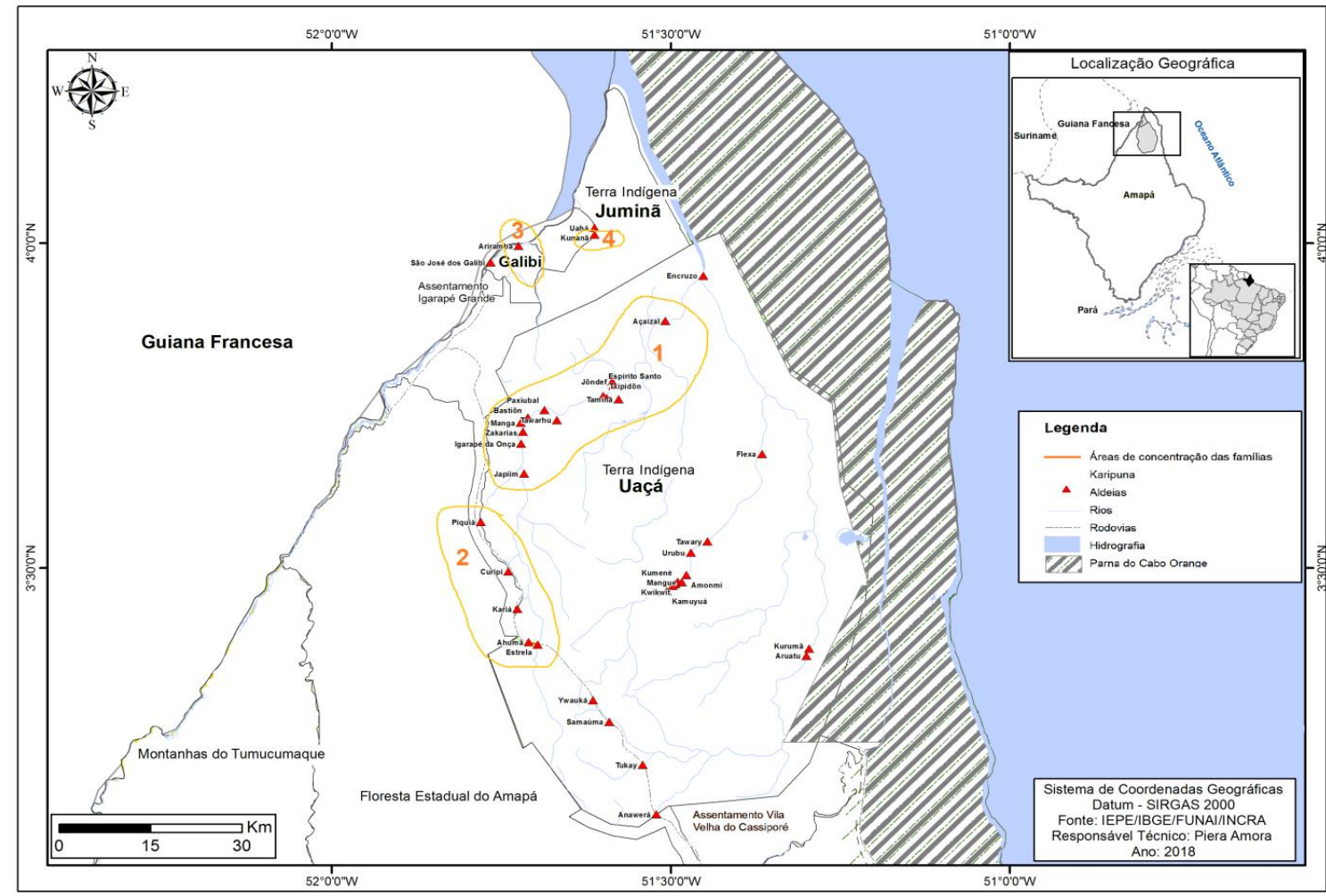

Revista Moara, n. 55, jan-jul 2020 ISSN: 0104-0944

Recebido em 16/03/2020

Avaliado em 10/07/2020 
Entre os indígenas Karipuna do Amapá, é possível encontrar falantes de português, de kheuól ${ }^{5}$ (crioulo de base francesa) e de francês (variedade da Guiana Francesa). Em sua maioria, este povo usa o português como L1 e o kheuól como L2, exceto na aldeia Espírito Santo, onde há a predominância do kheuól como L1.

Sobre a situação sociolinguística dos Karipuna do Amapá, em um estudo de base geolinguística e perceptual, Sanches (2019a) mostra que o uso do português é dominante na área indígena Karipuna quando comparado ao uso do kheuól. O autor constatou que a maioria dos colaboradores indígenas entrevistados acredita falar, escrever, compreender e ler bem em português. No entanto, quando se trata do kheuól, os colaboradores consideram a compreensão desta língua como satisfatória em relação às outras habilidades e competências linguísticas, já que boa parte não sabe ler e escrever em kheuól, além de falar pouco esta língua.

Outro fator interessante apontado por Sanches (2019a) está relacionado à aquisição do português e do kheuól. Para o autor, a escola indígena prioriza o ensino e uso do português em detrimento do kheuól. No entanto, essa hegemonia do português como primeira língua não se estende a todas as aldeias Karipuna. Como já mencionado, destaca-se, como exceção, a aldeia Espírito Santo que busca manter uma política linguística em prol do uso da língua kheuól.

Sanches e Day (2020), investigando de modo preciso as políticas linguísticas na área indígena dos Karipuna, constatam que os falantes indígenas ainda guardam uma representação positiva da língua, mantendo com ela vínculos identitários, além de reconhecerem o processo de perda linguística instaurado em função do uso contínuo do português nas comunidades. Fica evidente, assim, o fenômeno de diglossia ${ }^{6}$ na área indígena Karipuna em que o português é a variedade alta e o kheuól a variedade baixa.

Essa forte presença do português na área indígena Karipuna vem interferindo linguisticamente no uso do kheuól. Sanches (2019b) identifica a presença de lexias usadas no português local, que até então não tinham sido registradas como pertencente ao repertório da língua kheuól, e que aos poucos foram incorporadas ao kheuól,

\footnotetext{
${ }^{5}$ Alleyne e Ferreira (2007) concebem o Kheuól como uma variedade do Amazonian French Creole, interligado (em termos sócio-históricos e linguísticos) com o crioulo francês falado na Guiana Francesa.

${ }^{6}$ Quando há diferenças de status sociopolítico entre as duas ou mais línguas ou variedades.
} 
sobretudo por falantes jovens. É o caso, por exemplo, de lexicais como: raio, carrinho de mão, baladeira, pata-cega, jiral, pó compacto, bar, blush e ruge. O autor também registra lexias híbridas como: sehẽn (sereno), tãjerin (tangerina), mutõ (mutum), pikot (picote), lãbik (lambique), petek (peteca), papagai (papagaio), pip (pipa), balãse (balanço), vaz (vazo), privad (privada), sutxiẽ (sutiã), kuek (cueca), bikin (biquíni), ẽvalid (inválido), traves (travessa), vizaj (visagem), tramel (tramela) e baget (baguete).

\section{Metodologia da pesquisa}

Os procedimentos metodológicos apresentados aqui seguem o mesmo protocolo utilizado na elaboração do "Microatlas linguístico (Português-Kheuól) da área indígena do Amapá” (SANCHES, 2020a).

A seleção dos pontos de pesquisa foi feita a partir dos seguintes critérios: i) históricos; ii) socioculturais; iii) contato linguístico; iv) tempo de existência das localidades; v) localização geográfica; vi) e o número de falantes do Português-Kheuól.

Deste modo, foram selecionadas nove aldeias indígenas Karipuna localizadas em três Terras Indígenas (TI), no extremo norte do estado do Amapá. O quadro a seguir indica o nome das localidades, número de falantes e a Terra Indígena (TI) habitada.

Quadro 04 - Comunidades indígenas pesquisadas

\begin{tabular}{|c|c|c|c|}
\hline ALDEIA & LOCALIZAÇÃO & TERRA INDÍGENA & POPULAÇÃO \\
\hline 1. Manga & Rio Curipi & Uaçá & 1014 \\
\hline 2. Espírito Santo & Rio Curipi & Uaçá & 602 \\
\hline 3. Santa Izabel & Rio Curipi & Uaçá & 371 \\
\hline 4. Açaizal & Rio Curipi & Uaçá & 118 \\
\hline 5. Kunanã & Igarapé Juminã & Juminã & 96 \\
\hline 6. Ariramba & Rio Oiapoque & Galibi & 88 \\
\hline 7. Ahumã & BR 156 & Uaçá & 78 \\
\hline 8. Curipi & BR 156 & Uaçá & 64 \\
\hline 9. Kariá & BR 156 & Uaçá & 47 \\
\hline
\end{tabular}

Fonte: Sanches (2020a).

Os dados acima expressam somente as comunidades pesquisadas e o número aproximado de indígenas em cada uma delas. Com base nesses dados, presume-se que 
há um total de 1.000 indígenas falantes do kheuól, considerando os níveis de bilingualidade entre eles e acrescentando os indígenas do grupo Galibi-Marworno, também falantes desta língua.

Para escolha dos colaboradores, foram selecionados 36 falantes indígenas Karipuna estratificados socialmente, ou seja, para cada localidade foram entrevistados quatro indígenas: um homem e uma mulher de 18 a 30 anos; e um homem e uma mulher acima de 50 anos. Os colaboradores foram divididos em dois grupos: sexo (homens e mulheres) e idade (os de primeira faixa etária entre 18 a 30 anos; e os de segunda faixa etária acima de 50), conforme o quadro abaixo:

Quadro 05 - Perfil dos colaboradores

\begin{tabular}{|l|l|l|}
\hline \multicolumn{1}{|c|}{ COLABORADORES } & \multicolumn{1}{|c|}{ IDADE } & \multicolumn{1}{|c|}{ SEXO } \\
\hline $01-$ MA & $18-30$ anos & MASCULINO \\
\hline $02-$ FA & $18-30$ anos & FEMININO \\
\hline $03-$ MB & Acima de 50 anos & MASCULINO \\
\hline $04-$ FB & Acima de 50 anos & FEMININO \\
\hline
\end{tabular}

Em relação à documentação do corpus, foram utilizados três instrumentos de pesquisa, o primeiro corresponde à ficha do colaborador, o segundo ao questionário sociolinguístico do projeto Atlas Linguístico do Português falados em Área Indígena (ALiPAI), e o terceiro ao Questionário Semântico-Lexical do projeto Atlas Linguístico do Brasil (ALiB), este último foi adaptado para atender às necessidades do contexto da pesquisa.

Os dados coletados foram apresentados em arquivos de áudio formato MP3 e tratados com auxílio do programa computacional Audacity. Após a organização dos dados foi iniciado o processo de produção das cartas linguísticas com o auxílio do soft Corel DRAWX8.

O corpus selecionado para este trabalho diz respeito a dois itens lexicais do campo semântico vestuários e acessórios, o item 102 - Calcinha e o item 103 - Rouge. A seguir serão apresentadas as cartas lexicais referentes aos itens supracitados e suas respectivas descrições e análises. 


\section{Apresentação, descrição e análise da variação lexical}

O português falado em área indígena, numa perspectiva geolinguística, vem sendo objeto de estudo de dissertações de mestrado e teses de doutorado, sobretudo desenvolvidas dentro do Grupo de Pesquisa GeoLinTerm (Geossociolinguística e Socioterminologia) ${ }^{7}$, coordenado pelo Prof. Dr. Abdelhak Razky.

No cenário amapaense, no que tange ao léxico, cita-se o estudo de Rodrigues (2017), na área indígena dos Wajãpi, e, o de Sanches (2020a), na área indígena dos Karipuna do Amapá.

Sobre este último trabalho, apresenta-se aqui uma amostra da variação lexical do português falado por indígenas Karipuna, respectivamente sobre os itens calcinha e rouge.

$\mathrm{O}$ primeiro item analisado corresponde às denominações para calcinha em português. A pergunta feita aos colaboradores buscou registrar como eles chamam para "a roupa que a mulher usa debaixo da saia". Como respostas obtidas, foram registradas 31 ocorrências para calcinha, 4 para biquíni (biquinho) e 2 para ánagua. Conforme ilustra a Figura 02.

Figura 02 - Carta P102 (calcinha)

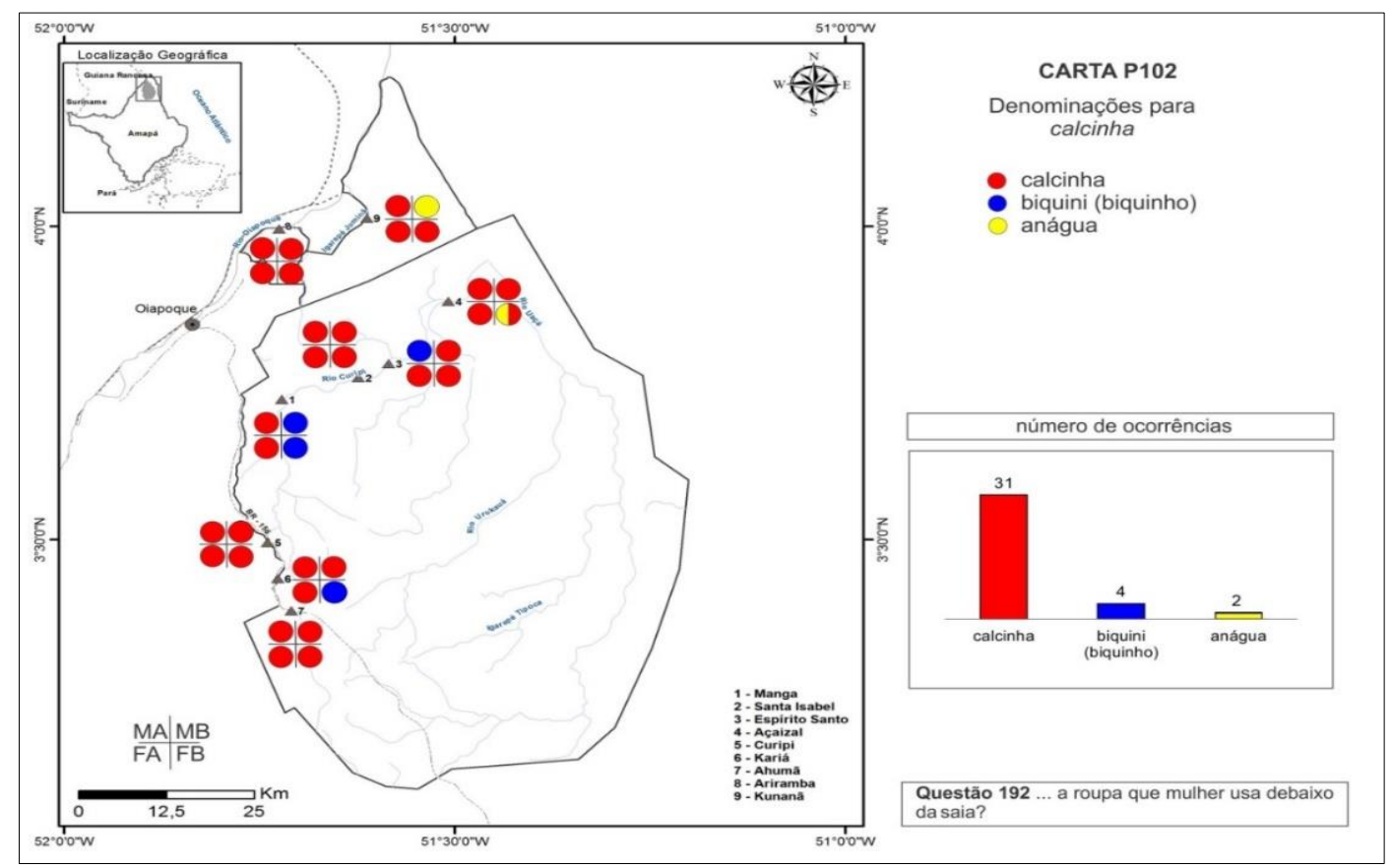

Fonte: Sanches (2020b).

${ }^{7}$ Para mais informações sobre o projeto consultar: https://geolinterm.com.br/

Revista Moara, n. 55, jan-jul 2020 ISSN: 0104-0944

Recebido em 16/03/2020

Avaliado em 10/07/2020 
O mapeamento apresentado acima aponta o uso predominante da variante calcinha tanto na fala de mulheres como na fala de homens, com pouca interferência da variável faixa etária. Todavia, vale destacar que, no caso da segunda variante, biquíni (biquinho), esta ocorreu quatro vezes, duas na aldeia Manga (01), uma na aldeia Espírito Santo (03) e uma na aldeia Kariá (06). Dessas quatro ocorrências, três delas foram mencionadas por colaboradores do sexo masculino.

Este cenário descrito pode ser interpretado a partir da constatação de que a peça de roupa íntima consiste em um acessório usado majoritariamente por mulheres. No caso da menção ao termo biquíni ${ }^{8}$, referido em maior parte por homens, destaca-se a relação semântica com o vocábulo calcinha, que corresponde também à peça de roupa íntima usada por mulheres, segundo conceitua Houaiss (2009, p. 294): “1. maiô de duas peças de tamanho reduzido, que cobrem o busto e a parte inferior do tronco. 2. calcinha feminina de dimensões reduzidas”. Para os colaboradores do sexo masculino, biquíni (biquinho) tem a mesma correlação semântica com a lexia calcinha, por isso, a variante biquíni (biquinho) apareceu como segunda opção lexical na fala dos homens.

Sobre a variante anágua, esta ocorreu duas vezes, uma na aldeia Açaizal (04), na fala de uma indígena mulher, de segunda faixa etária, e, outra na aldeia Kunanã (09), na fala de um indígena homem, de mesma faixa etária. De acordo com Nascentes (1955), anágua é uma palavra de origem hispânica, mais precisamente, uma forma primitiva originária de Cuba (Del Castillo), ou do Haiti, podendo ser entendida como uma peça da indumentária feminina, utilizada por baixo da roupa (vestido ou saia), com o objetivo de inibir a transparência, ou gerar volume.

Com base nos dados do ALiB, é possível inferir, como mostra Costa (2018, p. 128), que anágua pode ser considerada termo-sinônimo de calcinha, sendo, em sua maioria, pronunciado por mulheres idosas. Há também outros trabalhos geolinguísticos que sustentam essa afirmação (CRISTIANINI, 2007; MILANI, REZENDE, CRUZ, SILVA, 2015; NASCIMENTO, 2016).

O segundo item lexical analisado corresponde às denominações para rouge em português. Para isso, foi perguntado aos colaboradores como eles chamam "aquilo que as mulheres passam no rosto, nas bochechas, para ficarem mais rosadas". Como respostas foram registradas 22 ocorrências para pó compacto, 7 para maquiagem, 6 para

\footnotetext{
${ }^{8}$ Houaiss (2009, p. 294): "1. maiô de duas peças de tamanho reduzido, que cobrem o busto e a parte inferior do tronco. 2. Calcinha feminina de dimensões reduzidas". 
blush e 2 para talco. A variante pó compacto ocorreu em todas as localidades pesquisadas; maquiagem apareceu nas aldeias Manga (01), Santa Isabel (02), Espírito Santo (03) e Açaizal (04); blush foi mencionada em quase todas as aldeias pesquisadas exceto nas comunidades Açaizal (04), Curipi (05) e Kariá (06); e, talco ocorreu apenas na aldeia Manga (01) e Espírito Santo (03). Abaixo a Figura 02 sobre a variação lexical em questão.

Figura 03 - Carta P103 (rouge)

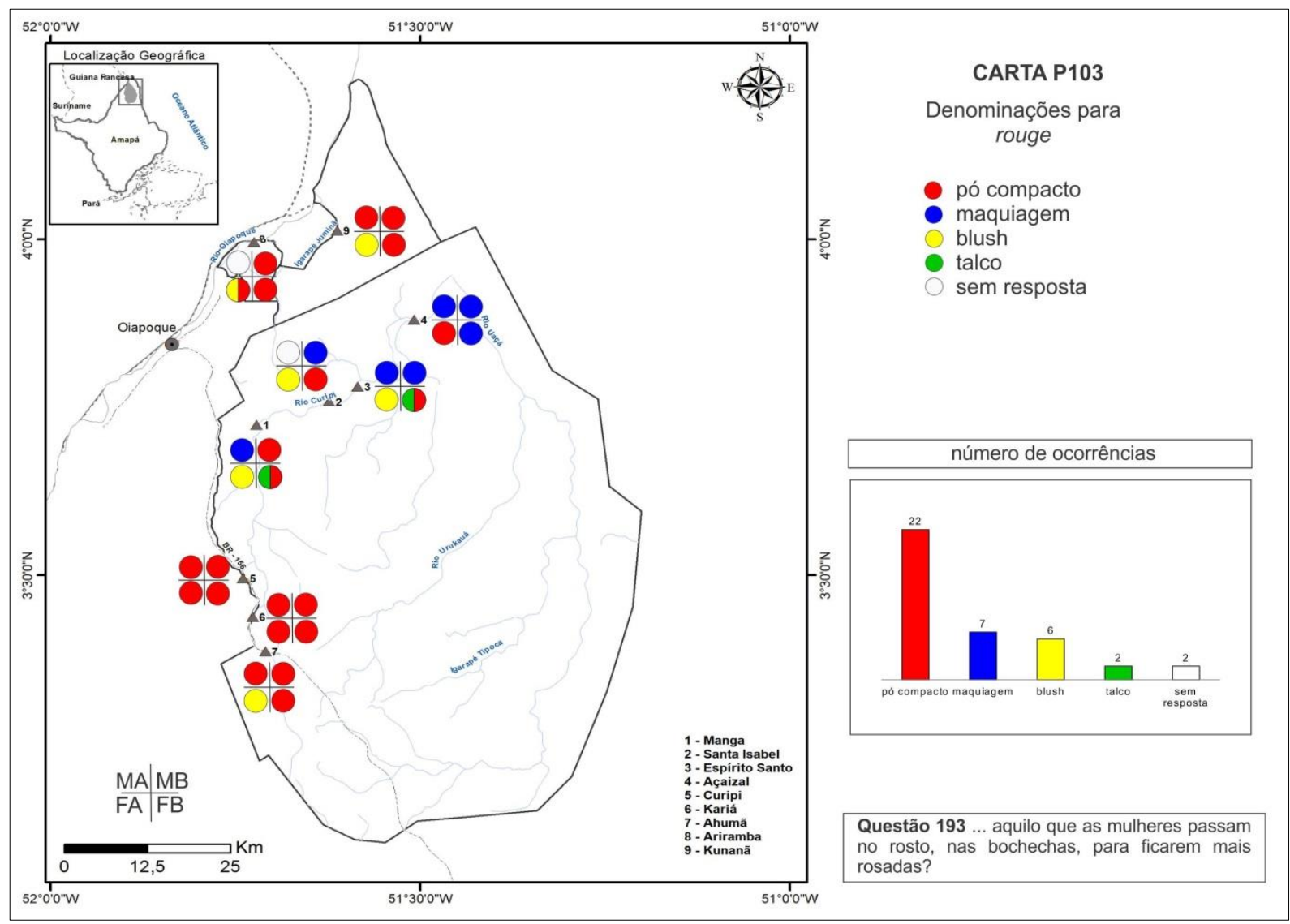

Fonte: Sanches (2020b).

A figura acima mostra que na fala de colaboradores de sexo masculino foram registradas as variantes pó compacto e maquiagem. Na fala de mulheres foram registradas, além daquelas mencionadas pelos homens, mais duas, blush e talco. Constatou-se que a menção feita a pó compacto ocorreu com leve tendência na fala de colaboradores do sexo feminino, com 12 ocorrências. No entanto, a variante maquiagem prevaleceu na fala de colaboradores de sexo masculino, com 6 ocorrências. Já as 
variantes blush e talco foram mencionadas somente na fala das mulheres, a primeira com 6 ocorrências e a segunda com 2 ocorrências.

Diante das variantes lexicais registradas para o item rouge, é possível apontar algumas considerações a respeito dessas ocorrências na fala de homens e de mulheres. Em hipótese, infere-se que pó compacto, blush e talco são as variantes que predominam na fala de mulheres em decorrência do contato e da utilização do produto pelo grupo feminino. Vale ressaltar que, no caso de blush e talco, outro fator social que pode condicionar o uso dessas variantes é a faixa etária ${ }^{9}$ dos colaboradores, uma vez que a variante blush predomina na fala de mulheres jovens, enquanto talco se sobressai na fala de mulheres idosas.

Em relação à variante maquiagem, esta se destacou na fala de colaboradores do sexo masculino, com acepção correlata à maquilagem ${ }^{10}$. Segundo Houaiss (2009, p. 1240), maquiagem trata-se de um: "conjunto de produtos cosméticos usado para maquilar". Conforme essa definição fica evidente que o uso da lexia maquiagem, em menção feita por homens, diz respeito a uma acepção genérica. A escolha lexical por maquiagem, presente na fala dos homens, também certamente está associada ao pouco contato do homem com este produto, uma vez que se trata de um utensílio, majoritariamente, de uso feminino.

Outra hipótese lançada a fim de explicar essa situação diz respeito aos tabus linguísticos ${ }^{11}$. Acerca do item rouge, o universo masculino indica forte resistência na pronúncia de determinadas lexias, consideradas por eles, do universo feminino. É exemplo disso, a rejeição feita ao uso das variantes blush e pó compacto. Nesse sentido, é possível inferir que, para o grupo masculino, especificar o nome dado a um produto de beleza usado por uma mulher enseja a possibilidade de que o homem possa ser julgado por seus pares, servindo de chacota, ou como alguém que também faz uso do produto. Essa resistência na fala dos homens torna visível a partir de entrevista concedida pelo colaborador $04 \mathrm{MB}$, que durante o evento, sugeriu que a pergunta fosse feita a sua esposa, posto que "a ela caberia dizer o nome do produto".

\footnotetext{
${ }^{9}$ Essa dimensão social será analisada no próximo subcapítulo.

${ }^{10}$ maquiagem é sinônimo/variante de maquilagem.

11 "Há duas definições de tabu linguístico - própria e imprópria. Propriamente, o tabu linguístico é a proibição de dizer certo nome ou certa palavra, aos quais se atribui poder sobrenatural, para evitar infelicidade ou desgraça. Impropriamente, o tabu linguístico é a proibição de dizer qualquer expressão imoral ou grosseira. O primeiro é mágico-religioso ou de crença, e o segundo é moral ou de sentimento" (GUÉRIOS, 1979, p. 05).
} 
INQ.: E como o senhor chama para aquilo que as mulheres passam no rosto pra ficar rosado?

INF.: ah! Isso aí eu não sei. Acho que é maquiagem.

INQ.: Mas não tem um nome específico pra isso? Ou é só maquiagem?

INF.: Só maquiagem mesmo... Pergunta pra ela aí (apontando para a esposa) que ela deve saber. Ela que usa isso.

INF.: O senhor só diz maquiagem mesmo?

INF.: Sim, só maquiagem... Isso é coisa de mulher (risos).

O trecho confirma a tabuização das variantes lexicais do item rouge, sobretudo, no que se refere ao da lexia maquiagem, considerada pelo colaborador 04MB como "coisa de mulher", logo, intangível ao homem.

\section{Considerações finais}

Os resultados desta pesquisa constataram que para o item lexical calcinha, os indígenas Karipuna tendem a usar em português, de forma predominante, a variante calcinha, e, em menor frequência, as variantes biquíni(biquinho) e anágua. Já para o item rouge, a predominância está no uso da variante pó compacto, seguida de maquiagem, blush e talco. A análise dessas variantes mostrou condicionadores externos influenciando o uso de certas lexias, como a variável sexo condicionando o uso biquíni(biquinho) e maquiagem, e a variável faixa etária condicionando o uso de anágua, blush e talco.

Com isso, as cartas lexicais apresentadas aqui mostraram tendências de uso conforme a idade e sexo dos colaboradores, apresentando também a vitalidade do português falado em área indígena. Pois, mesmo que não se tenha feita a análise das lexias encontradas na língua kheuól, é possível encontrar no mapeamento de Sanches (2020b) empréstimos lexicais de palavras em português na língua kheuól. No item calcinha, por exemplo, aparecem bikin, txilot/txilota e pãtaló, e para o item rouge foram registradas as variantes huj, po kõpakito, blush, makiaj e lapo the.

Como sugestão para novas pesquisas, pretende-se a partir do mapeamento geolinguístico já realizado em comunidades tradicionais, a intercomparação de cartas 
linguística com outros trabalhos de mesma natureza, a fim de ratificar ou refutar a ideia de contínuo lexical, tendo em vista que há variantes lexicais encontradas em área indígena ou afro-brasileira que se distinguem das variantes encontradas em área urbana.

Assim, este trabalho suscitou algumas questões como o de compreender até que ponto as variantes lexicais encontradas em área urbana são convergentes ou divergentes das encontradas em áreas indígenas. Em busca de respostas a esta pergunta, ratifica-se a importância do trabalho geolinguístico em área indígena. Uma vez que todo e qualquer registro científico do português falado em comunidades tradicionais servirá de "pista" para descrição e interpretação dos rumos que o português brasileiro vem traçando.

\section{REFERÊNCIAS}

ALLEYNE, M. C.; FERREIRA, J. A. S. Comparative perspectives on the origins, development and structure of Amazonian (Karipúna) French Creole. In: HUBER, M.; VIVEKA, V. (orgs.). Synchronic and diachronic perspectives on contact languages, vol. 32, p. 325-357. John Benjamins Publishing, 2007.

ALTENHOFEN, C. V.; THUN, H. As migrações e os contatos linguísticos na geografia linguística do Sul do Brasil Bacia do Prata. In: AGUILERA, V.de A.; ROMANO, V. P. A Geolinguística no Brasil: caminhos percorridos, horizontes alcançados. Londrina: Eduel, 2016, p. 371-392.

CAMPOY, J. M. H. La geolinguística: consideraciones sobre la dimensión espacial del linguaje. E.L.U.A., 13, 1999, p. 65-88.

CARDOSO, S. Geolinguística: tradição e modernidade. São Paulo: Parábola, 2010.

CHAMBERS, J. K.; TRUDGILL, P. La Dialectología. Madrid: Visor Libros, 1994.

COSTA, D. de S. S. Vocabulário Dialetal do Centro-Oeste: interfaces entre a Lexicografia e a Dialetologia. 2018. 353 f. Tese (Doutorado em Estudos da Linguagem) - Universidade Estadual de Londrina, Londrina/PR, 2018. 
CRISTIANINI, A. C. Atlas Semântico-lexical da região do Grande ABC. Tese (Doutorado em Linguística) Faculdade de Filosofia, Letras e Ciências Humanas da Universidade de São Paulo, São Paulo, 2007.

FERrEIRA, A. B. de H. O Novo Dicionário Aurélio da Língua Portuguesa. 3. ed. Editora Positivo, 2009.

GUÉRIOS, R. F. M. Tabus Linguísticos. 2. ed. São Paulo: Ed. Nacional; Curitiba: Editora da Universidade Federal do Paraná, 1979.

MILANI; S. E.; REZENDE, T. F.; CRUZ, A. da; SILVA, D. M. da. Atlas Linguístico de Goiás (ALINGO): léxico-fonético. Rio de Janeiro: Barra Livros, 2015.

NASCENTES, A. Dicionário etimológico da língua portuguesa. Rio de Janeiro: Francisco Alves, 1955.

NASCIMENTO, G. E. Designações para sutiã, calcinha e cueca por falantes da cidade de Mutuípe: perspectiva dialetológica. Monografia (Graduação em Letras). Universidade Federal do Recôncavo da Bahia, 2016.

RODRIGUES, M. D. G. Mapeamento lexical do português falado pelos Wajãpi no estado do Amapá: uma abordagem geossociolinguística. Programa de Pós-Graduação em Letras, 2017.

SANCHES, R D. Microatlas linguístico (português-kheuól) da área indígena dos Karipuna do Amapá - volume 1. Tese (Doutorado). Belém-PA: Universidade Federal do Pará (Programação de Pós-Graduação em Letras), 2020a.

SANCHES, R D. Microatlas linguístico (português-kheuól) da área indígena dos Karipuna do Amapá - volume 2. Tese (Doutorado). Belém-PA: Universidade Federal do Pará (Programação de Pós-Graduação em Letras), 2020 b.

SANCHES, R. D. Bilinguismo entre os Karipuna do Amapá numa perspectiva geoliguística. In: OLIVEIRA, E. dos S.; VASCONCELOS, E. A.; SANCHES, R. D. (Orgs.). Estudos Linguísticos na Amazônia. Campinas, SP: Pontes Editores, 2019a. 
SANCHES, R. Empréstimos linguísticos no português e no Kheuól falados pelo povo Karipuna do Amapá. SOUZA, S.; PESSOA, L.; CALAZANS, P.; RIBEIRO, C. Bilinguismos em cena: línguas em interação. Rio Branco - AC: NEPAN Editora, 2019b. p. 39-52. (No prelo).

SANCHES, R. D.; DAY, K. C. N. Políticas linguísticas na área indígena dos Karipuna do Amapá: o caso do Kheuól. Revista Linguagem \& Ensino, Pelotas, v. 23, n. 4, out.-dez. 2020. (No prelo).

THUN, H. A dialetologia pluridimensional no Rio da Prata. In: ZILLES, A. M. S. (Org.). Estudos de variação linguística no Brasil e no Cone Sul. Porto Alegre: Editora da UFRGS, 2005. p. 63-92.

THUN, H. La geolingüística como lingüística variacional general (con ejemplos del Atlas lingüístico Diatópico y Diastrático del Uruguay). Congresso Internazionale Di Linguistica e Filologia Romanza, 21, 1995, Palermo. In: RUFFINO, G. (org.). Atti. Tübingen: Niemeyer, 1998. p. 701-729.

THUN, H. Variety complexes in contact: A study on Uruguayan and Brazilian Fronterizo. In: AUER, Peter; SCHMIDT, E. (eds.). Language and space: An International Handbook of Linguistic Variation. Vol. 1: Theories and methods. Berlin: De Gruyter Mouton, 2010. p. 706-723. 